\section{JURNAL EKONOMI EFEKTIF}

ISSN : $2622-8882$, E-ISSN : 2622-9935

Jurnal Ekonomi Efektif, Vol. 3, No. 1, Oktober 2020 @Prodi Manajemen Fakultas Ekonomi Universitas Pamulang

\title{
PENGARUH KEGIATAN PROMOSI TERHADAP KEPUTUSAN PEMBEIAN PADA PT. INDOTEX MANDIRI DI TANGERANG
}

\author{
Mahnun Mas'adi \\ Universitas Pamulang \\ dosen01017@unpam.ac.id
}

\begin{abstract}
ABSTRAK
Penelitian ini bertujuan untuk mengetahui pengaruh kegiatan promosi terhadap keputusan pembeian pada PT. Indotex Mandiri di Tangerang. Metode yang digunakan adalah explanatory research dengan sampel sebanyak 96 responden. Teknik analisis menggunakan analisis statistik dengan pengujian regresi, korelasi, determinasi dan uji hipotesis. Hasil penelitian ini variabel kegiatan promosi diperoleh rata-rata skor sebesar 3,40 dengan kriteria baik. Variabel keputusan pembeian diperoleh rata-rata skor sebesar 3,82 dengan kriteria baik. Kegiatan promosi berpengaruh signifikan terhadap keputusan pembeian dengan persamaan regresi $\mathrm{Y}=7,639+0,900 \mathrm{X}$, dan nilai korelasi 0,791 atau kuat dengan determinasi $62,6 \%$. Uji hipotesis diperoleh signifikansi $0,000<0,05$.
\end{abstract}

Kata Kunci: Kegiatan Promosi, Keputusan Pembelian.

\begin{abstract}
This study aims to determine the effect of promotional activities on purchasing decisions at PT. Indotex Mandiri in Tangerang. The method used is explanatory research with a sample of 96 respondents. The analysis technique uses statistical analysis with regression testing, correlation, determination and hypothesis testing. The results of this research variable promotional activities obtained an average score of 3.40 with good criteria. The purchasing decision variable obtained an average score of 3.82 with good criteria. Promotional activities have a significant effect on purchasing decisions with the regression equation $Y=7.639+$ $0.900 X$, and a correlation value of 0.791 or strong with a determination of $62.6 \%$. Hypothesis testing obtained a significance of $0.000<0.05$.
\end{abstract}

Keywords: Promotion Activities, Purchasing Decisions. 


\section{PENDAHULUAN}

\section{A. Latar Belakang Masalah}

Pakaian merupakan salah satu kebutuhan pokok sehari-hari masyarakat. Untuk memenuhi kebutuhan tersebut masyarakat membelinya dari toko-toko terdekat. PT. Indotex Mandiri merupakan agen grosir pakaian yang menjual produk dengan cara online maupun offline yang menjual dalam jumlah besar maupun satuan dengan sistem ini PT. Indotex Mandiri dapat menyuplai pakaian baik didalam maupun diluar wilayah Tangerang melalui sistem penjulan secara langsung maupun tidak langsung.

Faktor promosi yang dilakukan oleh perusahaan menjadi sangat penting karena pPromosi merupakan suatu bentuk komunikasi pemasaran, dimana komunikasi pemasaran adalah aktivitas pemasaran yang berusaha menyebarkan informasi, mempengaruhi, membujuk mengingatkan pasar atas perusahaan atau produknya agar bersedia menerima, membeli dan loyal pada produk yang ditawarkan, (Fandy Tjiptono, 2007:103).

Setiap usaha atau langkah yang dilakukan perusahaan adalah untuk memuaskan konsumen, perusahaan dituntut untuk melakukan strategi pemasaran yang tepat agar mempunyai suatu produk yang memiliki keunggulan dari pesaingnya dan juga perusahaan harus menyampaikan informasi tentang produk-produknya agar dapat menarik konsumen yang potensial sehingga dapat mempertahankan dan meningkatkan hasil penjualan perusahaan.

Salah satu kegiatan pemasaran yang cukup efektif dan efisien adalah promosi. Menurut Freddy Rangkuti (2012:50), promosi adalah "Kegiatan penjualan dan pemasaran dalam rangka menginformasikan dan mendorong permintaan terhadap produk, jasa dan ide dari perusahaan dengan cara mempengaruhi konsumen agar mau membeli produk dan jasa yang dihasilkan oleh perusahaan".

Promosi merupakan salah satu faktor yang sangat penting, karena promosi dapat mempengaruhi secara langsung terhadap kelancaran maupun keberhasilan perusahaan dalam mencapai tujuannya. Oleh karena itu kelancaran maupun keberhasilan suatu perusahaan sangat tergantung pada manajemen didalam membuat rencana kegiatan promosi yang akan datang, baik jangka pendek maupun jangka panjang.

Dengan adanya promosi yang terencana, maka perusahaan dapat mendekati pembeli atau calon konsumen agar mau membeli produk yang mereka tawarkan. Disamping itu promosi erat kaitannya dengan kelangsungan hidup suatu perusahaan. Promosi yang berhasil sebenarnya tidak hanya mampu meningkatkan hasil penjualan semata-mata, akan tetapi dapat memberikan keuntungan-keuntungan lain seperti nama perusahaan akan dikenal oleh masyarakat dan hasil produksinya dapat meningkatkan efisiensi penggunaan modal kerja, memperkecil piutang, dan lain-lain. Dan sebaliknya jika strategi tidak berhasil, maka dapat menyebabkan kenaikan biaya per unit, keuntungan yang diperoleh dalam tiap unit menurun sehingga dengan sendirinya penghasilan perbulan pun menurun.

Masih banyak masyarakat yang belum mengetahui secara jelas tentang berbagai macam produk yang dimiliki PT. Indotex Mandiri, untuk itu diharapkan kegiatankegiatan promosi yang dilakukan dapat mengenai sasaran dengan tepat, guna memberikan informasi mengenai produk pakaian secara jelas, sehingga masyarakat mendapatkan informasi yang dalam mengenai produk pakaian di PT. Indotex Mandiri, promosi dimaksudkan untuk menarik minat beli masyarakat, antara lain dengan memberikan informasi selengkapnya kepada masyarakat akan suatu produk yang dipasarkan. Jika kegiatan promosi terlaksana dengan baik, maka masyarakat akan tertarik dan akan membeli produk tersebut. Cara memperkenalkan produk terhadap masyarakat 
dapat mengadakan acara-acara promosi seperti sosialisasi produk, pameran, sharing session produk didaerah-daerah yang lebih luas lagi jangkauannya dan masih banyak lagi acara lainnya yang dapat dilaksanakan guna memperkenalkan produk kepada masyarakat.

Diharapkan dengan dilaksanakanya kegiatan promosi, minat beli masyarakat akan meningkat, dikarenakan dengan tumbuhnya rasa tertarik masyarakat akan produk yang ditawarkan pada acara-acara promosi yang diselengarakan tersebut. Dalam berbagai kegiatan promosi yang dilakukan PT. Indotex Mandiri sebisa mungkin sebagai penyelenggara acara, harus dapat membuat kegiatan promosi menjadi menarik.

Kegiatan promosi dilakukan guna memberikan informasi kepada masyarakat yang masih belum mengenal produk secara jelas, didukung dengan penyajian programprogram promosi lainnya yang berhubungan dengan produk yang dipasarkan. Hal ini diharapkan dapat menorong minat beli masyarakat akan suatu produk, minat beli masyarakat diharapkan akan berubah, dari yang sebelumnya tidak berminat untuk membeli menjadi berminat untuk membeli. Effendy (Effendy, 2003:305) mendefinisikan minat sebagai. "Kelanjutan dari perhatian yang merupakan titik tolak bagi timbulnya hasrat (desire) untuk melakukan suatu kegiatan yang diharapkan komunikator". Hal yang kontradiktif justru terjadi di perusahaan diantaranya kegiatan-kegiatan promosi yang dilakukan PT. Indotex Mandiri dalam mempengaruhi minat beli masyarakat masih sangat minim, minat beli masyarakat cenderung berkurang sehingga mengurangi omzet penjualan.

Hal ini dipengaruhi oleh kegiatan yang dilakukan contohnya menyelenggrakan program sosialisasi produk sebagai ajang memberikan informasi mengenai produk lama yang sudah ada dengan tujuan agar manfaat dari produk dapat digunakan dengan baik dan benar oleh pelanggan, selain itu untuk menarik minat pelanggan PT. Indotex Mandiri juga meyelenggarakan acara- acara untuk memperkenalkan produk barunya. Cara ini dimaksudkan untuk memberikan gambaran terhadap masyarakat akan produk, dan agar lebih menarik perhatian pelanggan, penyelenggaraan disarankan dapat menyediakan berbagai macam hadiah yang dapat menarik minat masyarakat. Dengan demikian penulis tertarik untuk mengadakan riset lebih lanjut, adapun judul penelitian yang penulis lakukan adalah "Pengaruh Kegiatan Promosi Terhadap Minat Beli Pada PT. Indotex Mandiri di Tangerang"

\section{B. Rumusan Masalah}

1. Bagaimana kegiatan promosi pada pada PT. Indotex Mandiri di Tangerang?.

2. Bagaimana keputusan pembeian pada PT. Indotex Mandiri di Tangerang ?.

3. Adakah pengaruh antara kegiatan promosi terhadap keputusan pembeian pada PT. Indotex Mandiri di Tangerang?.

\section{Tujuan Penelitian}

1. Untuk mengetahui kondisi kegiatan promosi pada PT. Indotex Mandiri di Tangerang ?.

2. Untuk mengetahui kondisi keputusan pembeian pada PT. Indotex Mandiri di Tangerang?.

3. Untuk mengetahui pengaruh antara kegiatan promosi terhadap keputusan pembeian pada PT. Indotex Mandiri di Tangerang?. 


\section{METODE PENELITIAN}

\section{Populasi}

Populasi dalam penelitian ini berjumlah 96 responden PT. Indotex Mandiri di Tangerang

2. Sampel

Teknik pengambilan sampling dalam penelitian ini adalah samplel jenuh, dimana semua anggota populasi dijasikan sebagai sampel. Dengan demikian sampel dalam penelitian ini berjumlah 96 responden.

\section{Jenis Penelitian}

Jenis penelitian yang dipakai adalah asosiatif, dimana tujuannya adalah untuk mengetahui mencari keterhubungan antara variabel independen terhadap variabel dependennya

\section{Metode Analisis Data}

Dalam menganalisis data digunakan uji validitas, uji reliabilitas, analisis regresi linier sederhana, koefisien korelasi, koefisien determinasi dan uji hipotesis.

\section{HASIL PENELITIAN DAN PEMBAHASAN}

\section{Analisis Deskriptif}

Pada pengujian ini digunakan untuk mengetahui skor minimum dan maksimum skor tertinggi, ratting score dan standar deviasi dari masing-masing variabel. Adapun hasilnya sebagai berikut:

Tabel 1. Hasil Analisis Descriptive Statistics Descriptive Statistics

\begin{tabular}{|c|c|c|c|c|c|}
\hline & $\mathrm{N}$ & $\begin{array}{c}\text { Minimu } \\
\mathrm{m}\end{array}$ & $\begin{array}{c}\text { Maximu } \\
\mathrm{m}\end{array}$ & Mean & $\begin{array}{c}\text { Std. } \\
\text { Deviation }\end{array}$ \\
\hline Kegiatan Promosi (X) & 96 & 28 & 44 & 34.02 & 3.742 \\
\hline Keputusan Pembelian (Y) & 96 & 29 & 49 & 38.27 & 4.259 \\
\hline Valid N (listwise) & 96 & & & & \\
\hline
\end{tabular}

Kegiatan promosi diperoleh varians minimum sebesar 28 dan varians maximum 44 dengan ratting score sebesar 3,40 dengan standar deviasi 3,742.

Keputusan pembeian diperoleh varians minimum sebesar 29 dan varians maximum 49 dengan ratting score sebesar 3,82 dengan standar deviasi 4,259.

\section{Analisis Verifikatif.}

Pada analisis ini dimaksudkan untuk mengetahui pengaruh variabel independen terhadap variabel dependen. Adapun hasil pengujian sebagai berikut:

\section{a. Analisis Regresi Linier Sederhana}

Uji regresi ini dimaksudkan untuk mengetahui perubahan variabel dependen jika variabel independen mengalami perubahan. Adapun hasil pengujiannya sebagai berikut:

Tabel 2. Hasil Pengujian Regresi Linier Sederhana

\section{Coefficients $^{\mathbf{a}}$}

\begin{tabular}{|c|c|c|c|c|c|}
\hline \multirow[b]{2}{*}{ Model } & \multicolumn{2}{|c|}{$\begin{array}{l}\text { Unstandardized } \\
\text { Coefficients }\end{array}$} & \multirow{2}{*}{$\begin{array}{c}\text { Standardized } \\
\text { Coefficients } \\
\text { Beta }\end{array}$} & \multirow[b]{2}{*}{$\mathrm{t}$} & \multirow[b]{2}{*}{ Sig. } \\
\hline & $\mathrm{B}$ & Std. Error & & & \\
\hline 1 (Constant) & 7.639 & 2.458 & & 3.108 & .002 \\
\hline $\begin{array}{l}\text { Kegiatan } \\
\text { Promosi (X) }\end{array}$ & .900 & .072 & .791 & 12.537 & .000 \\
\hline
\end{tabular}

a. Dependent Variable: Keputusan Pembelian (Y) 
Berdasarkan hasil pengujian pada tabel di atas, diperoleh persamaan regresi $\mathrm{Y}$ $=7,639+0,900 \mathrm{X}$. Dari persamaan tersebut dijelaskan sebagai berikut:

1) Konstanta sebesar 7,639 diartikan jika kegiatan promosi dan motivasi tidak ada, maka telah terdapat nilai keputusan pembeian sebesar 7,639 point.

2) Koefisien regresi kegiatan promosi sebesar 0,900 , angka ini positif artinya setiap ada peningkatan kegiatan promosi sebesar 0,900 maka keputusan pembeian juga akan mengalami peningkatan sebesar 0,900 point.

\section{b. Analisis Koefisien Korelasi}

Analisis koefisien korelasi dimaksudkan untuk mengetahui tingkt kekuatan hubungan dari variabel independen terhadap variabel dependen baik secara parsial maupun simultan. Adapun hasil pengujian sebagai berikut:

Tabel 3. Hasil Pengujian Koefisien Korelasi Kegiatan promosi Terhadap

\section{Keputusan pembeian.}

\begin{tabular}{llrr} 
& \multicolumn{1}{c}{ Correlations $^{\mathbf{b}}$} & \multicolumn{1}{c}{$\begin{array}{r}\text { Kegiatan } \\
\text { Promosi }(\mathrm{X})\end{array}$} & $\begin{array}{c}\text { Keputusan } \\
\text { Pembelian }(\mathrm{Y})\end{array}$ \\
\hline Kegiatan Promosi (X) & Pearson Correlation & 1 & $.791^{* \star}$ \\
\cline { 2 - 4 } & Sig. (2-tailed) & & .000 \\
\hline Keputusan Pembelian (Y) & Pearson Correlation & $.791^{* \star}$ & 1 \\
\cline { 2 - 4 } & Sig. (2-tailed) & .000 & \\
\hline
\end{tabular}

**. Correlation is significant at the 0.01 level (2-tailed).

b. Listwise $\mathrm{N}=96$

Berdasarkan hasil pengujian diperoleh nilai korelasi sebesar 0,791 artinya kegiatan promosi memiliki hubungan yang kuat terhadap keputusan pembeian.

\section{c. Analisis Koefisien Determinasi}

Analisis koefisien determinasi dimaksudkan untuk mengetahui besarnya persentase pengaruh dari variabel independen terhadap variabel dependen. Adapun hasil pengujian sebagai berikut:

Tabel 4. Hasil Pengujian Koefisien Determinasi Kegiatan promosi Terhadap Keputusan pembeian. Model Summary

\begin{tabular}{lr|rr|r} 
Model & \multicolumn{2}{c}{$\begin{array}{c}\text { Adjusted R } \\
\text { Square }\end{array}$} & \multicolumn{2}{c}{$\begin{array}{c}\text { Std. Error of the } \\
\text { Estimate }\end{array}$} \\
\hline 1 & R Square & .626 & .622 & 2.619 \\
\hline a. Predictors: (Constant), Kegiatan Promosi (X1) &
\end{tabular}

a. Predictors: (Constant), Kegiatan Promosi (X1)

Berdasarkan hasil pengujian diperoleh nilai determinasi sebesar 0,626 artinya kegiatan promosi memiliki kontribusi pengaruh sebesar $62,6 \%$ terhadap keputusan pembeian.

\section{d. Uji Hipotesis}

Pengujian hipotesis dengan uji t digunakan untuk mengetahui hipotesis mana yang diterima.

Rumusan hipotesis: Terdapat pengaruh yang signifikan antara kegiatan promosi terhadap keputusan pembeian. 


\begin{tabular}{|c|c|c|c|c|c|}
\hline \multirow[b]{3}{*}{ lodel } & \multicolumn{3}{|c|}{ Coefficients ${ }^{a}$} & \multirow[b]{3}{*}{$\mathrm{t}$} & \multirow[b]{3}{*}{ Sig. } \\
\hline & \multicolumn{2}{|c|}{$\begin{array}{l}\text { Unstandardized } \\
\text { Coefficients }\end{array}$} & \multirow{2}{*}{$\begin{array}{c}\text { Standardized } \\
\text { Coefficients } \\
\text { Beta }\end{array}$} & & \\
\hline & B & Std. Error & & & \\
\hline (Constant) & 7.639 & 2.458 & & 3.108 & .002 \\
\hline Kegiatan Promosi $(\mathrm{X})$ & .900 & .072 & .791 & 12.537 & .000 \\
\hline
\end{tabular}

Berdasarkan hasil pengujian pada tabel di atas, diperoleh nilai t hitung $>\mathrm{t}$ tabel atau $(12,537>1,986)$, dengan demikian hipotesis yang diajukan bahwa terdapat pengaruh yang signifikan atara kegiatan promosi terhadap keputusan pembeian diterima.

\section{PEMBAHASAN HASIL PENELITIAN}

\section{Kondisi Jawaban Responden Variabel Kegiatan promosi}

Berdasarkan jawaban responden, variabel kegiatan promosi diperoleh ratting score sebesar 3,40 berada di rentang skala 3,40 - 4,19 dengan kriteria baik atau setuju.

\section{Kondisi Jawaban Responden Variabel Keputusan pembeian}

Berdasarkan jawaban responden, variabel keputusan pembeian diperoleh ratting score sebesar 3,82 berada di rentang skala 3,40-4,19 dengan kriteria baik atau setuju.

\section{Pengaruh Kegiatan promosi Terhadap Keputusan pembeian}

Kegiatan promosi berpengaruh signifikan terhadap keputusan pembeian dengan persamaan regresi $\mathrm{Y}=17,517+0,565 \mathrm{X}$, nilai korelasi sebesar 0,791 atau memiliki hubungan yang kuat dengan kontribusi pengaruh sebesar 62,6\%. Pengujian hipotesis diperoleh nilai thitung $>\mathrm{t}$ tabel atau $(12,537>1,986)$. Dengan demikian hipotesis yang diajukan bahwa terdapat berpengaruh signifikan antara kegiatan promosi terhadap keputusan pembeian diterima.

\section{PENUTUP}

\section{Kesimpulan}

a. Variabel kegiatan promosi diperoleh ratting score sebesar 3,40 berada di rentang skala 3,40 - 4,19 dengan kriteria baik atau setuju.

b. Variabel keputusan pembeian diperoleh ratting score sebesar 3,82 berada di rentang skala 3,40 - 4,19 dengan kriteria baik atau setuju.

c. Kegiatan promosi berpengaruh signifikan terhadap keputusan pembeian dengan persamaan regresi $\mathrm{Y}=17,517+0,565 \mathrm{X}$, nilai korelasi sebesar 0,791 atau kuat dan kontribusi pengaruh sebesar $62,6 \%$ sedangkan sisanya sebesar $57,9 \%$ dipengaruhi faktor lain. Uji hipotesis diperoleh nilai $t$ hitung $>t$ tabel atau $(12,537>1,986)$.

\section{Saran}

a. Kegiatan Promosi PT. Indotex Mandiri harus lebih diperhatikan dan ditingkatkan lagi, terutama dalam hal tingkat manfaat kupon yang diberikan dan Tingkat pemberian Barang Iklan yang masih belum terlalu disukai oleh Pelanggan, untuk itu PT. Indotex Mandiri harus segera mengganti atau mengadakan perbaikan, dan jangan terlalu dibiarkan terlalu lama.

b. Minat beli Masyarakat harus lebih ditumbuhkan dan ditingkatkan kembali, karena tingkat keinginan menggunakan produk serta tingkat pengaruh kualitas masih rendah 
maka harus dapat segera diselesaikan agar tujuan yang dicapai bisa dapat tercapai atau bahkan bisa melewati target yang diinginkan.

\section{DAFTAR PUSTAKA}

Algifari. (2015). "Analisis Regresi untuk Bisnis dan Ekonomi”. Yogyakarta: BPFE.

Arikunto, Suharsimi (2014). "Prosedur Penelitian Suatu Pendekatan Praktek". Jakarta: Rineka Cipta.

Bashu Swastha dan T. Handoko (2015) Manajemen Pemasaran Moderen, Yogyakarta: BPFE.

Basu Swastha Dharmmesta. (2014). Manajemen Pemasaran. BPFE: Yogyakarta. Buchari Alma. 2014. Manajemen pemasaran dan Pemasaran Jasa. Edisi Revisi.

Bilson Simamora (2016) Panduan Riset Prilaku Konsumen, Jakarta: PT. Gramedia Pustaka.

Fandy Tjiptono (2017), Serivce Quality and Satisfiation. Jakarta: Edisi tiga. Andi.

Freddy Rangkuti (2016) Strategi Promosi Yang Kreatif, Edisi Pertama, Cetakan Pertama Jakarta: Gramedia Pustaka Utama.

Imam Ghozali (2017). "Aplikasi Analisis Multivariate Dengan Program SPSS”. Edisi Kelima. Semarang: Badan Penerbit Undip.

Istijanto (2014) "Riset Sumber Daya Manusia”. Jakarta: PT. Gramedia Pustaka

Kharis, Ismu Fadli (2011). "Studi Mengenai Impulse Buying dalam Penjualan Online”. Semarang : Skripsi Universitas Diponegoro

Kotler dan Amstrong (2017), Prinsip-prinsip Pemasaran. Edisi Kedua Belas”. Jilid Satu. Jakarta: Erlangga.

Lukiastuti, Fitri, et.al (2020). The Influence of Entrepreneur's Personal Characteristics on SMES Performance Mediated by Entrepreneurial Orientation. International Journal of Psychosocial Rehabilitation. Volume 24 - Issue 8

Lupiyoadi (2016) Manajemen Pemasaran Jasa, Edisi 4, Jakarta: Salemba Empat.

Philip Kotler (2017) Manajemen Pemasaran, Edisi Keempat Belas, Jakarta: PT. Indeks.

Phipil Kotler dan Kevin Keller (2017) Manajemen Pemasaran, Edisi Kedua Belas, Jilid Satu, Jakarta: Erlangga.

Rao, Purba, (2012). “Measuring Consumer Perceptions Through Factor Analysis”, The Asian.

Santoso, Singgih (2015). "Menguasai Statistik Multivariat”. Jakarta: PT Elex Media Komputindo.

Sudjana (2014) “Metode Statistika”, Bandung: Tarsido.

Sugiyono (2017), "Metode Penelitian Administrasi : dilengkapi dengan Metode $R \&$ D”. Bandung: Alfabeta.

Suhartanto (2014). "Metode Riset Pemasaran”. Bandung: Alfabeta

Sunarsi, D. (2016, October). Pengaruh Minat, Motivasi Dan Kecerdasan Kognitif Terhadap Prestasi Belajar (Studi Kasus Pada Mahasiswa Program Studi S-1 Manajemen. Fakultas Ekonomi. Universitas Pamulang. Thn. Akademik 2015-2016). In Proceedings (Vol. 1, No. 1).

Sunarsi, D. (2017). Pengaruh Rekrutmen, Seleksi dan Pelatihan Terhadap Produktivitas Kerja Karyawan PT Mercolade Tangerang.

Sunarsi, D. (2018). Pengembangan Sumber Daya Manusia Strategik \& Karakterisrik Sistem Pendukungnya: Sebuah Tinjauan. Jurnal Ilmiah MEA (Manajemen, Ekonomi, \& Akuntansi). Vol 2 No 3 